\title{
IRADIATOR STTN: OVERVIEW DESAIN MANAJEMEN KESELAMATAN DAN KESEHATAN KERJA
}

\author{
Fifi Nurfiana ${ }^{1}$, Sugili Putra ${ }^{1}$, Joanne Salres ${ }^{1}$, Fazlur Ansyari' ${ }^{1}$, Said Wigo A. ${ }^{1}$ \\ 1) Program Studi Teknokimia Nuklir STTN-BATAN Yogyakarta \\ fifi.nurfiana@batan.go.id
}

\begin{abstract}
ABSTRAK
IRADIATOR STTN: OVERVIEW DESAIN MANAJEMEN KESELAMATAN DAN KESEHATAN KERJA. Iradiator gamma STTN dapat memberi kebermanfaatan yang besar sebagai fasilitas yang mendukung tridharma perguruan tinggi. Namun secara bersamaan memiliki potensi resiko karena membawa sumber radioaktif yang cukup besar yakni Co-60 12 kiloCurie. Oleh karena itu, dalam penggunaan fasilitas iradiator harus disusun dan diterapkan sistem manajemen keselamatan dan kesehatan kerja (SMK3) dalam rangka pengendalian risiko yang berkaitan dengan kegiatan kerja dengan sumber radiasi, guna tercipta tempat kerja yang aman, efisien dan produktif. Dari penggabungan semua sistem K3 dan penjaminan mutu yang mengacu pada garis peraturan yang berlaku maka dapat ditarik empat pilar manajeman dalam pemanfaatan Iradiator STTN yang meliputi planning (perencanaan), organizing (pengorganisasian), leading (pengarahan) dan controlling (pengendalian). Dalam hal ini planning meliputi pemilihan tipe irradiator, desain ruang/bangun, dan kualifikasi SDM; organizing dilakukan dengan adanya struktur organisasi pengelola irradiator; leading dengan pengarahan untuk optimalisasi pelayanan; dan controlling yang meliputi kontrol terhadap pengoperasian, perawatan, data personil, dan paparan lingkungan.
\end{abstract}

Kata kunci: iradiator, gamma, manajemen, keselamatan, kesehatan.

\begin{abstract}
STTN'S IRRADIATOR: OVERVIEW OF WORK SAFETY AND HEALTH MANAGEMENT DESIGN. STTN's gamma irradiator can provide great benefits as a facility that supports three educational principles. But simultaneously it has potential risk because it carries a large enough radioactive source, Co6012 kiloCurie. Therefore, in the use of irradiator facilities, work safety and health management system must be prepared in order to control risks that come with work activities, in order to create a safe, efficient and productive workplace. From safety systems and quality assurance that refers to the applicable regulatory line, four management pillars can be drawn in the use of STTN's Iradiator which includes planning, organizing, leading and controlling. In this case, planning includes the selection of irradiator type, building design, and $H R$ qualifications; organizing is done by the irradiator management organization structure; leading with direction to optimize service; and controlling which includes control of operations, maintenance, personnel data, and environmental exposure.
\end{abstract}

Key words: irradiator, gamma, management, safety, health.

\section{PENDAHULUAN}

Iradiator adalah perangkat peralatan pemancar radiasi dengan sumber radionuklida pemancar gamma atau pesawat akselerator pembangkit sinar-X dan/atau berkas elektron, yang digunakan untuk tujuan penelitian, sterilisasi/pasteurisasi, polimerisasi maupun untuk pengawetan bahan makanan. Sekolah Tinggi Teknologi Nuklir (STTN) Yogyakarta pada tahun 2017 melakukan pengadaan fasilitas iradiator yang menjadi bagian dari Laboratorium Kimia Radiasi. Fasilitas ini digunakan untuk mendukung proses belajar mengajar, penelitian dosen dan pengabdian masyarakat dalam upaya untuk mengoptimalkan kegiatan tri dharma perguruan tinggi tersebut.

Iradiator STTN merupakan iradiator kategori I bermerek Ob-servo Ignis dari 
Hungaria yang menggunakan sumber radioaktif Co-60 12 kiloCurie. Iradiator memancarkan radiasi berenergi tinggi/ radiasi pengion berupa sinar gamma.

Shimura et al (2013) menyebutkan bahwa bahaya radiasi sinar gamma dapat mengakibatkan efek somatik dan efek genetik. Efek somatik terdiri dari efek segera dan efek tertunda. Efek segera diantaranya adalah sindrom radiasi akut termasuk di dalamnya cedera sumsum tulang, cedera saluran gastrointestinal dan cedera kardiovaskular. Selain itu efek segera yang mungkin muncul adalah rontoknya rambut, luka bakar pada kulit dan kelainan janin. Sementara efek tertunda seperti katarak, kanker dan leukimia. Efek yang diterima akan pada bergantung pada dosis yang terserap (efek deterministik), namun ada pula yang bersifat probability (efek stokastik).

Efek bahasa radiasi tersebut dapat timbul karena operasi rutin ataupun karena terjadinya kecelakaan (Ramana, 2009). Ramana juga menyebutkan untuk mencegahnya perlu dipastikan keamanan operasi dan sumber radioaktif dengan memastikan desain reaktor dan kelengkapannya, pengamanan kondisi darurat, keandalan pekerja dan pembiasaan budaya keselamatan di lingkungan kerja.

Selain pertimbangan teknis diperlukan juga sebuah regulasi untuk pengendalian pemanfaatan sumber radioaktif. Badan Pengawas Tenaga Nuklir (BAPETEN) sebagai lembaga pengawas penggunaan fasilitas radiasi mengatur tentang dosis maksimal atau biasa dikenal dengan Nilai Batas Dosis (NBD) yang dapat diterima oleh pekerja radiasi; pekerja magang untuk pelatihan kerja, pelajar, atau mahasiswa yang berumur 16 (enambelas) tahun sampai dengan 18 (delapanbelas) tahun; dan anggota masyarakat. NBD bagi setiap orang tersebut berbeda-beda dan telah diatur dalam Peraturan Kepala BAPETEN Nomor 4 tahun 2013 tentang Proteksi dan Keselamatan Radiasi dalam Pemanfaatan Tenaga Nuklir. Dalam pembanguan fasilitas iradiator juga harus memenuhi izin kontruksi dan ijin operasi sesuai dengan Keputusan Kepala BAPETEN Nomor 11/Ka-BAPETEN/VI-99 tentang Izin Konstruksi dan Operasi Iradiator.

Oleh karena itu, dalam penggunaan fasilitas nuklir termasuk fasilitas iradiator harus disusun dan diterapkan Sistem Manajemen Keselamatan dan Kesehatan Kerja (SMK3) dalam rangka pengendalian risiko yang berkaitan dengan kegiatan kerja guna terciptanya tempat kerja yang aman, efisien dan produktif sesuai Peraturan Pemerintah Republik Indonesia Nomor 50 tahun 2012 tentang Penerapan Sistem Manajemen Keselamatan dan Kesehatan Kerja. Selain mengacu pada Perka BAPETEN penyusunan SMK3 juga harus didasarkan pada SNI ISO/IEC 9001:2015 tentang Sistem Manajemen Mutu dan OHSAS 18001:2007 tentang Sistem Manajemen Keselamatan dan Kesehatan Kerja. Hal tersebut untuk menjamin mutu proses iradiasi dan mencegah terjadinya kecelakaan dari bahaya penggunaan fasilitas iradiator.

Dari penggabungan semua sistem K3 dan penjaminan mutu yang mengacu pada garis peraturan yang berlaku maka dapat ditarik empat pilar manajemen moderen seperti yang dirumuskan oleh Griffin (2016) dalam pemanfaatan Iradiator STTN yang meliputi planning (perencanaan), organizing (pengorganisasian), leading (pengarahan) dan controlling (pengendalian).

Kajian ini diharapkan dapat memberi manfaat dalam pendayagunaan fasilitas iradiator khususnya sebagai referensi untuk penerapan dan pengembangan sistem manajemen keselamatan dan kesehatan kerja iradiator ke depannya.

\section{METODE}

Penyusunan kajian ini dilakukan dengan mempelajari peraturan perundangan yang berlaku terkait konstruksi, pengoperasian dan pemanfaatan iradiator dan sumber radioaktif serta, litelatur lain yang berkaitan serta naskah akademik pengadaan iradator STTN.

\section{HASIL DAN PEMBAHASAN}

Fungsi sistem manajemen planning (perencanaan), organizing (pengorganisasian), leading (pengarahan) dan controlling (pengendalian) dalam sistem keselamatan dan kesehatan kerja pendayagunaan iradiator.

\section{Planning}

Perencanaan (planning) dilakukan terhadap bahaya paparan radiasi yang diterima oleh pekerja dan masyarakat umum di sekitar fasilitas iradiator STTN sejak sebelum Iradiator datang. Desain ruangan dibuat sedemikian untuk meminimalisir akses dan paparan radiasi 
pada keadaan normal dan keadaan darurat serta dengan membuat sistem keamanan berganda dari kunci hingga CCTV. STTN secara lembaga juga menyiapkan pekerja/personil tersertifikasi yang akan bertanggungjawab terhadap sistem operasional Iradiator Gamma STTN.

a. Pemilihan tipe iradiator

STTN memilih iradiator kategori I jenis Ob-Servo Ignis buatan Hungaria karena memiliki keunggulan dalam pengangkutan, yaitu antara houshing dengan sumber dapat dilakukan pengangkutan terpisah sebab $\mathrm{Ob}-$ Servo Ignis didesain secara knockdown. Dengan sistem ini maka Ob-Servo Ignis akan lebih aman dan mudah penanganannya ketika dilakukan pengangkutan. Apalagi dengan sistem pemuatan sumber yang dapat dilakukan di tempat (tidak dimiliki oleh iradiator jenis lain) maka selain keamanan dan penanganannya yang mudah juga ketika aktivitas sumbernya sudah habis maka tinggal dilakukan pemesanan sumbernya saja. Keunggulan ini sangat menarik mengingat STTN pada saat ini belum memiliki kolam yang dapat digunakan untuk penggantian sumber.

Berdasarkan analisis resiko, material kontainer (biological shielding) iradiator Ob-servo Ignis merupakan alloy logam yang sangat kuat dan mampu menahan radiasi dari sumber, serta menjaga sumber tetap di dalam kontainer. Sumber Co-60 juga dalam bentuk sealed keramik. Hal ini membuat iradiator dan sumber radioaktif akan tetap aman dari kondisi darurat seperti gempa, banjir, maupun kebakaran.

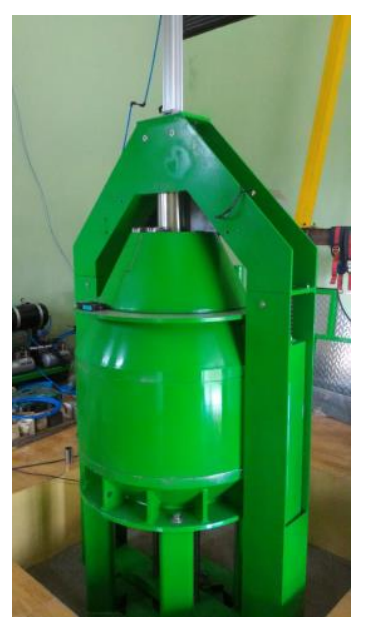

Gambar 1. Iradiator tipe $1 \mathrm{Ob}-$ Servo Ignis dari Hungaria (Sugili Putra, 2016) b. Desain bangunan dan ruang iradiator berdasarkan analisis resiko

Iradiator mempunyai persyaratan teknis dalam penempatannya. Setelah dilakukan survei dan penelaahan ruangan yang telah tersedia saat ini di STTN, menunjukkan bahwa tidak ada satupun ruangan yang memenuhi syarat untuk meletakkan iradiator yang akan dibeli. Oleh karena itu, agar dapat meletakkan iradiator tersebut maka harus dilakukan pembangunan ruangan baru. Beberapa pertimbangan yang harus dipenuhi dalam pembangunan gedung ini diantaranya adalah:

- Letak bangunan harus memenuhi persyaratan keamanan dari BAPETEN.

- Mempunyai nilai estetika yang baik dan menyatu dengan desain gedung utama.

- Dilengkapi dengan ruangan teori yang dapat menampung mahasiswa sebanyak lebih kurang 30 orang.

Untuk keperluan tersebut, maka telah dilakukan desain bangunan gedung dengan tata letak ruangan seperti pada gambar 2 .

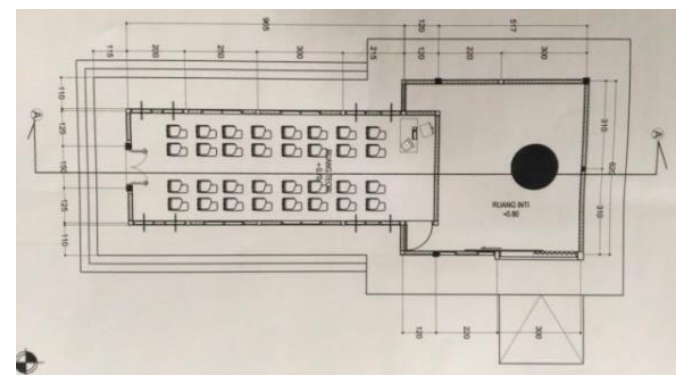

Gambar 2. Tata ruang gedung iradiator (Sugili Putra, 2016)

Selain itu pembangunan gedung juga didasarkan analisis resiko seperti kemungkinan munculnya gas ozon sebagai akibat dari reaksi radiasi dengan udara. Hal ini diantisipasi dengan adanya ventilasi udara di bagian atas ruangan. Resiko lain timbul akibat kebakaran sehingga keseluruhan material gedung dibuat dari material yang tidak mudah terbakar. Bentuk fisik bangunan adalah seperti terlihat pada gambar 3. 


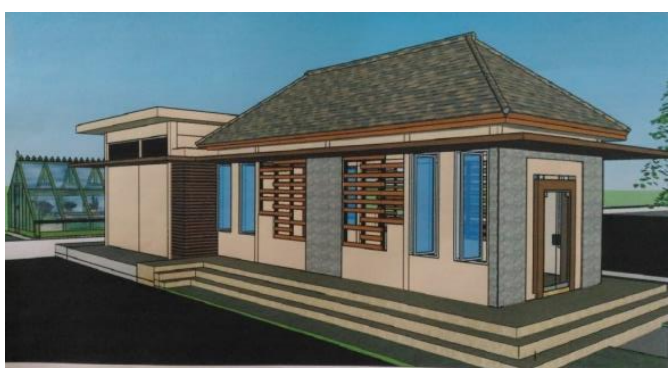

Gambar 3. Desain gedung iradiator (Sugili Putra, 2016)

Gedung iradiator juga dilengkapi dengan sistem kontrol, sistem pneumatik dan kompressor, main swich box dengan power supply untuk menjaga jika terjadi mati listrik dari PLN. Selain itu gedung iradiator juga dilengkapi peralatan pendukung keamanan untuk mencegah sabotase dan akses penggunaan tidak sah seperti kunci ganda acces control, door moving system, detektor gerakan, CCTV, dan sistem alarm.

c. Pemenuhan kualifikasi dan pelatihan personel

Personel yang bertugas melaksanakan pengelolaan iradiator gamma adalah Operator Iradiator, Petugas Perawatan Iradiator, Petugas Dosimetri Iradiator, Supervisor Iradiator, dan Petugas Proteksi Radiasi (PPR). STTN menyediakan personil tersebut sesuai dengan persyaratan yang ditetapkan BAPETEN.

Sebelum bekerja di bidang tersebut, petugas iradiator tersebut wajib mengikuti pelatihan untuk memperoleh sertifikasi keahlian dari PSMN BATAN dan Surat Izin Bekerja (SIB) dari BAPETEN. Selama bertugas dalam pengelolaan iradiator gamma, SIB dan sertifikasi keahlian harus selalu diperbarui sesuai ketentuan waktu yang ditetapkan. Pelatihan-pelatihan lain yang diprogramkan dan diselenggarakan oleh Ketua STTN serta wajib diikuti oleh personel yang bertugas di Iradiator adalah :

- Pelatihan Proteksi Radiasi

Sebelum pekerja radiasi melakukan kegiatan yang berhubungan dengan radiasi, pekerja wajib mengikuti pelatihan proteksi radiasi. Para pengajar pelatihan proteksi radiasi berasal dari Pusdiklat BATAN.

- Penyegaran Proteksi Radiasi
Setelah bekerja dengan radiasi dalam kurun waktu tertentu, secara berkala pekerja radiasi harus mengikuti pelatihan penyegaran proteksi radiasi. Para pengajar pelatihan ini berasal dari STTN.

- Pelatihan Penanggulangan Keadaan Darurat

Pelatihan penanggulangan keadaan darurat dilakukan minimal sekali dalam setahun, dan dalam pelatihan ini melibatkan para pekerja radiasi yang ada di STTN dan Kawasan Nuklir Yogyakarta.

- Pelatihan Keamanan Sumber Radioaktif (KSR)

Pelatihan KSR wajib diikuti oleh petugas iradiator untuk memperoleh pengetahuan sehubungan dengan sistem KSR yang dipasang di iradiator.

Dengan pelatihan ini STTN telah menyiapkan SDM yang capable sehingga proses pendayagunaan iradiator dapat berjalan dengan baik. Selain itu dalam sisi perencanaan STTN juga menyiapkan sistem manajemen yaitu struktur organisasi pengelola iradiator, sistem operasional/pendayagunaan irradiator, dan sistem manajemen $\mathrm{K} 3$ seperti yang tertera dalam OHSAS 18001:2007.

\section{Organizing}

STTN bertanggung jawab menetapkan dan melaksanakan Program Jaminan Kualitas Fasilitas Iradiasi Iradiator. Pelaksana program ini dibentuk dengan struktur organisasi yang bertanggung jawab terhadap penyelenggaraan dan pelaksanaan Program Jaminan Kualitas pada seluruh kegiatan pengelolaan Iradiator.

Secara Organisasi, Ketua STTN mengeluarkan Surat Keputusan terkait pengelola Fasilitas Iradiator Gamma STTN yang meliputi Kepala Fasilitas Iradiator, Operator, Petugas Perawatan, Petugas Dosimetri, Petugas Proteksi Radiasi, Petugas Keamanan Sumber Radioaktif dan Petugas Administrasi. Petugas pengelola ini bertanggung jawab terhadap penyelenggaraan dan pelaksanaan Program Jaminan Kualitas pada seluruh kegiatan pengelolaan iradiator. Setiap personil telah memiliki keahlian tersertifikasi dan distribusi tugasnya masingmasing dalam pemanfaatan dan pendayagunan Iradiator Gamma STTN. 
Komponen yang terlibat dalam organisasi iradiator adalah:

a. Pengusaha Instalasi Nuklir, adalah Ketua STTN yang memiliki izin pemanfaatan tenaga nuklir dari BAPETEN dan bertanggungjawab menetapkan Program Jaminan Kualitas Iradiator Gamma STTN.

b. Kepala Fasilitas Iradiator, adalah personel yang bertanggungjawab terhadap kelancaran penyelenggaraan Program Jaminan Kualitas Iradiator Gamma STTN dan kondisi alat serta kegiatan layanan iradiasi.

c. Petugas Proteksi Radiasi, adalah personel yang mempunyai lisensi PPR dari BAPETEN dan ditunjuk oleh Ketua STTN BATAN untuk mengawasi pengelolaan Iradiator Gamma STTN, yang berhubungan dengan proteksi dan keselamatan radiasi.

d. Pekerja Iradiator, yang terdiri dari Operator Iradiator, Petugas Perawatan Iradiator, Petugas Dosimetri Iradiator, dan Supervisor Iradiator serta Petugas Keamanan Sumber Radioaktif

- Operator Iradiator, adalah personel yang memiliki kualifikasi Surat Izin Bekerja (SIB) dari BAPETEN dan bertugas melakukan kegiatan pengoperasian iradiator.

- Petugas Perawatan Iradiator, adalah personel yang memiliki kualifikasi Surat Izin Bekerja (SIB) dari BAPETEN dan bertugas melakukan kegiatan perawatan iradiator.

- Petugas Dosimetri Iradiator, adalah personel yang memiliki kualifikasi Surat Izin Bekerja (SIB) dari BAPETEN dan bertugas melakukan kegiatan dosimetri iradiator.

- Supervisor Iradiator adalah personel yang memiliki kualifikasi keahlian sebagai supervisor Iradiator yang dikeluarkan oleh PSMN BATAN dan bertugas melakukan kegiatan pengawasan pengelolaan iradiator.

- Petugas Keamanan Sumber Radioaktif adalah personel yang memiliki kualifikasi Surat Izin Bekerja (SIB) dari BAPETEN dan bertugas melakukan kegiatan pengawasan keamanan sumber radioaktif iradiator.

Dalam menyusun sistem organisasi pengelola irradiator tersebut STTN menerapkan
ISO 9001:2015 yaitu prinsip manajemen mutu kepemimpinan, keterlibatan orang, pendekatan proses, dan manajemen hubungan.

\section{Leading}

Pendayagunaan Fasilitas Iradiator STTN meliputi pelayanan iradiasi untuk penelitian internal STTN dan pelayanan iradiasi untuk kerjasama penelitian. Selain itu juga didukung dengan adanya standar operasional prosedur (SOP) di setiap tahapan. Hal ini akan menjamin bahwa keseluruhan proses pemanfaatan akan terorganisasi dengan baik, membentuk budaya keselamatan di antara pekerja dan memenuhi prinsip leading (pengarahan) sehingga memenuhi standar keselamatan dan kesehatan terhadap bahaya radiasi.

Pada pelayanan iradiasi untuk penelitian internal STTN, input data penelitian (sampel) dan jadwal iradiasi ditentukan oleh mahasiswa atau dosen. Setelah sampel dicek dan mendapatkan rekomendasi untuk melakukan iradiasi. Sampel diiradiasi dengan dosis sesuai dengan permintaan yang akan diinput oleh operator. Saat iradiator beroperasi PPR dan petugas dosimetri melakukan pemantauan terhadap laju dosis dan laju paparan.

Pada pelayanan iradiasi eksternal, STTN membuat konsep sebagai kerjasama penelitian sehingga pengguna eksternal tidak dikenakan satuan biaya tetapi membuat kerjaama penelitian dengan STTN (dosen). Hal ini sekaligus diharapkan untuk menaikkan produktivitas riset dan keilmuan SDM STTN melalui kolaborasi riset tersebut.

Desain alur pelayanan eksternal ini adalah pelanggan menyampaikan sampel kepada petugas administrasi. Sampel dicek dengan adanya surat kerjasama penelitian yang dibuat dan ditunjuk oleh dosen STTN sebagai peneliti pendampingnya, jika sudah lengkap maka petugas administrasi menghubungi petugas iradiator yaitu PPR, operator, dan petugas dosimetri. Jika sudah masuk dalam jadwal penggunaan iradiator maka pelanggan menyerahkan sampel kepada peneliti STTN selaku pendamping dan sampel diserahkan kepada operator. Operator melakukan iradiasi sesuai jadwal dengan petugas yang sudah dihubungi oleh petugas administrasi. Setelah itu sampel diserahkan kepada peneliti STTN lalu diserahkan kepada pelanggan.

Penting untuk dibuat alur (SOP) dan info grafis pelayanan iradiasi untuk penelitian 
internal STTN untuk memudahkan peneliti atau pengguna iradiator. Alur pelayanan iradiasi ini harus disusun berdasarkan prinsip manajemen mutu berbasis fokus pada pelanggan seperti yang tercantum pada ISO 9001:2015.

\section{Controlling}

Dalam hal controlling, STTN menetapkan dan memelihara prosedur pengendalian dokumen sesuai OHSAS 18001:2007 poin 3.5 tentang dokumen. Rekaman terkait pemanfaatan dan pendayagunaan iradiator meliputi data operasi dan data personil terlibat, data perawatan, data dosimetri dosis radiasi, data paparan yang diterima personil, dan lain sebagainya. Kesemua data terarsip dan terkendalikan sehingga dapat dirunut sedemikian jika diperlukan.

a. Controlling terhadap pengoperasian irradiator

Standar Operasional Prosedur pengoperasian iradiator perlu dibuat untuk dijadikan panduan/pedoman oleh setiap petugas pengoperasian (operator) dalam mengoperasikan Iradiator Gamma STTN, dengan baik dan benar sesuai dengan kriteria keselamatan. Ruang lingkup SOP ini mencakup persiapan pengoperasian, pengoperasian untuk layanan iradiasi, dan keadaan darurat jika terjadi listrik mati.

Dalam persiapan pengoperasian iradiator gamma ada standar operasional yang harus dilaksanakan dan harus sesuai dengan dasar hukum, kualifikasi khusus personil, peralatan dan perlengkapan yang harus dibawa, serta pencatatan dan pendataan.

Controlling terhadap pengoperasian iradiator bertujuan agar setiap operasi iradiator gamma berjalan sesuai dengan SOP dan menjaga keselamatan serta kesehatan kerja pengguna. Dalam menjaga itu dibutuhkan Log Book data pengoperasian iradiator gamma sehingga proses controlling dapat berjalan dengan baik.

b. Controlling terhadap perawatan iradiator

Standar Operasional Prosedur perawatan iradiator perlu dibuat untuk mendapatkan cara kerja yang seragam, teratur dan terarah dalam melaksanakan perawatan peralatan iradiator, sehingga menjamin unjuk kerja yang maksimal dan umur pakai Iradiator Gamma STTN menjadi lebih panjang. Juga harus disiapkan Log Book perawatan sebagai data otentik perawatan alat.

Ruang lingkup SOP Perawatan Iradiator Gamma STTN adalah mengatur tentang bagaimana perawatan terhadap Iradiator Gamma STTN dilakukan. Perawatan Iradiator Gamma STTN ini sesuai dengan Manual Operasi dan Perawatan Iradiator Type OB-Servo Ignis meliputi perawatan harian, mingguan dan tahunan.

c. Controlling terhadap data paparan lingkungan

Dalam menjaga keselamatan dan kesehatan kerja penguna iradiator maka dibutuhkan controlling terhadap data paparan lingkungan. Controlling ini bertujuan sebagai acuan personel dalam menjaga diri terhadap paparan yang terjadi di lingkungan kerja iradiator sehingga dapat tahu berapa lama waktu yang diperbolehkan berada di laboratorium iradiator gamma.

Untuk controlling paparan lingkungan dibutuhkan area monitor sebagai alat yang akan menginformasikan jumlah paparan yang sedang terjadi di lingkungan kerja iradiator. Sehingga dengan informasi itu dapat meningkatkan mutu keselamatan dan kesehatan kerja di fasilitas iradiator.

\section{d. Controlling data personil}

Pemantauan dosis yang diterima oleh personil didasarkan pada PERKA BAPETEN No. 4 Tahun 2013 dimana ratarata Nilai Batas Dosis (NBD) pekerja radiasi tidak lebih dari $20 \mathrm{mSv}$ dalam per tahun dalam periode 5 (lima) tahun. Untuk mengetahui nilai ini, setiap personal mengenakan personal dosimeter (TLD) yang dianalisis berkala setiap 3 (tiga) bulan dan dijumlahkan setiap tahun juga lima tahunnya untuk masing-masing personil. Selain itu juga dilakukan pemeriksaan kesehatan personil secara berkala setiap tahun untuk menjamin kesehatan pekerja.

Data rekaman hasil controlling dijadikan dasar untuk melakukan perbaikan apabila memang dibutuhkan. Kegiatan pada fungsi pengendalian seperti mengevaluasi keberhasilan dan target dengan cara mengikuti standar indikator yang sudah ditetapkan, 
melakukan klarifikasi dan koreksi terhadap penyimpangan yang ditemukan, memberi alternatif solusi yang mungkin bisa mengatasi masalah yang terjadi.

Jika seluruh aspek manajemen keselamatan dan kesehatan kerja serta jaminan mutu yang meliputi planning, organizing, leading dan controlling terpenuhi diharapkan pendayagunaan iradiator STTN dapat berjalan baik dan selamat, berkontribusi terhadap perkembangan iptek di Indonesia.

\section{KESIMPULAN}

Berdasarkan hasil kajian dan analisis dari berbagai sumber data dan dikaitkan dengan sistem manajemen keselamatan dan kesehatan kerja fasilitas Iradiator Gamma STTN untuk menjaga pekerja radiasi, pekerja magang, dan anggota masyarakat umum agar tidak menerima paparan melebih nilai batas dosis yang telah ditetapkan oleh BAPETEN serta penjaminan mutu pemanfaatan iradiator dapat disimpulkan bahwa pengendalian bahaya radiasi dan penjaminan mutu dalam pemanfaatan fasilitas iradiator dapat dilakukan dengan:

1. Planning: pemilihan tipe irradiator, desain ruang/bangun, dan kualifikasi SDM;

2. Organizing: adanya struktur organisasi pengelola irradiator;

3. Leading: pengarahan untuk optimalisasi pelayanan; dan

4. Controlling: pengoperasian, perawatan, data personil, dan paparan lingkungan.

\section{DAFTAR PUSTAKA}

1. T. Shimura, I. Yamaguchi, H. Terada, et al., "Radiation occupational health interventions offered to radiation workers in response to the complex catastrophic disaster at the Fukushima Daiichi Nuclear Power Plant", Journal of Radiation Research, vol. 56, No. 3, pp. 413-421, 2015.

2. M.V. Ramana, "Nuclear Power: Economic, Safety, Health, and Environmental Issues of Near Term Technologies" Annu. Rev. Environ. Resour., vol. 34, pp. 127-152, 2009.

3. R. W. Griffin. Fundamentals of Management, Eighth Edition. Chengage Learning USA, 2015.
4. Keputusan Kepala BAPETEN Nomor 11/Ka-BAPETEN/VI-99 tentang Izin Konstruksi dan Operasi Iradiator.

5. Peraturan Kepala BAPETEN Nomor 4 tahun 2013 tentang Proteksi dan Keselamatan Radiasi dalam Pemanfaatan Tenaga Nuklir.

6. Peraturan Pemerintah Republik Indonesia Nomor 50 tahun 2012 tentang Penerapan Sistem Manajemen Keselamatan dan Kesehatan Kerja.

7. SNI ISO/IEC 9001:2015 tentang Sistem Manajemen Mutu.

8. Putra, Sugili, dkk. Naskah Akademik Pengadaan Iradiator Gama Jurusan Teknokimia Nuklir STTN-BATAN. STTNBATAN, 2016.

9. Noname. (30 May 2017). OB-SERVO IGNIS. Available: http://www.izotop.hu/?p=5034 
JURNAL FORUM NUKLIR (JFN) VOLUME 11, NOMOR 2, NOVEMBER 2017 